\title{
Influence of Material on Indian Stone Culture
}

\author{
BY ALLAN J, HUDSON, Mortlach, Sask.
}

It may be heresy but to me it's an open question whether it's an advantage to have read much about old world Archaeology before studying our own in Saskatchewan. One acquires a set of ideas which at best has to be modified or abandoned, and at worst makes for a fine archaeological indigestion. What point is there, for instance, in the classic distinction between flake and core tools.

The earliest stone workers fashioning rude chopping tools would detach flakes that could and would have to be used unretouched as simple cutting and scraping tools, but the more modern stone worker with his knowl edge of all the methods that had been evalued of handling stone used the detached pieces as cores for a whole series of tools, so that by the time he had made a blade or blades from a block of good material he would have obtained material for points, scrapers, awls, cutting flakes, oblique knives etc. At first he would detach shapeless pieces that would perhaps be completely refashioned as points, scrapers, ovates and so forth. But as pointed out before, as chipping proceeds he begins to detach flakes with one side already chipped. Where two flat flake scars intersect at an angle, a ridge is formed. By detaching a thin flake, starting back from the junction point, an awl or boring tool with a thin flake finger grip is obtained, and these are found in large number, some having been retouched and improved. Or if the stone-worker starts further back and deeper, a large piece is removed that could be rechipped to res emble an Aurignacian -- type scraper. Small bits could be rechipped to make nondescript scrapers of no special design and many of the smaller flint scrapers are obviously of this origin.

While the majority of points are compl etel y refashioned material occasionally a flat flake is rechipped just sufficiently to form a point and some oblique knives are plainly so made. Perhaps in a country where first class material was plentiful the stone worker could afford to be prodigal with his material and an apparent distinction maintained between flake and core tools, but not here.

The Indians could only afford to be wasteful with the substitute materials like quartzite. In the exhibit which I have prepared for the Regina Museum the results of the process described can be seen and studied.

In support of this new theory of evolution. Sir Arthur Kieth says that archaeologists find that the distribution of stone tools in definitely localized. That is not the impression I get here where the Indian stone culture was remarkably generalized rather than specialized. If that was in part due to the kind of life followed by the Indians it was certainly influenced by the wide diversity of stone materials they had to use for tools.

If most of the time the Indians of this area were able to find sufficient stones of the chalcedony group for the smaller tools, for the larger ones, substitute and inferior rocks had to be used extensively. It is not unusual to encounter as surface finds, worked chopping tools, five to six pounds in weight, the material being quartzite, basalt or rhyolite.

of a group of seventy-nine points obtained from unstratified digging at Campsite 2, in 1950, nineteen could be classed as flint though two or three of these are probably from the better parts of agatized wood, about thirty are an opaque quartz, the rest a re chert, jasper, agatizee wood, quartizite, basalt, and clear chalcedony.

of a group of two hundred scrapers from unstratified digging, one half of the smaller ones are flint, one third of the slightly larger are also flint. From the bottom zone of the same site, of a group of fifty-one only six are flint. of another one hundred and forty-five scrapers, forty are flint, the rest various materials, including one crystal quartz, a very difficult material from the stone-working angle., of another group of fifty-two scrapers from the same zone, only six are flint.

In general there is less flint in the larger tools and the older zones. Scrapers are the commonest tools round the firehearths, which perhans, could be expected. In addition to the methods described in making scrapers, very often they are just split pebbles with some secondary chipping, and frequently if there was enough material left on the base of a broken point, this was rechipped to form a scraper or cutting tool.

To sum up to a definite concl usion: the Indian stone-working industry was completely nationalis tic in its methods. The workers combined all methods with great flexibility to produce every kind 
of result from so-called Chellean handaxes to the finest drills. A curious instance of this flexibility is the only ground point I have which is on Card $B, 1950$, Campsite 2, stratified, line left 6 , No 2 from the left. (Provincial Muse um exhibit). Apparentl y the maker in the process of chipping found that any further work would ruin the point, so he finished it by grinding half the body.

So rationalistic was the Indian attitude to his stone industry that when he has acquired the white man's metal culture he seems to have lost all knowledge of the ancient art in a remarkably short space of time. There is a record of an Indian in the U. S. expressing the same superstition as was form erly current in Europe where artifacts when found used to be called "thunderstones"' Yet the Indians in some parts must have been still using stone points, certainly not much more than a hundred years ago. I suppose the average Indian of today would regard with contempt a collection of stone tools which his not very di stant ancestors had to use and which we so industriously collect. It seems to me there is a fine irony in it someplace.

M. A. Kittle, of Keewaten, Ontario is so interested in the welfare of the BL UE JAY thathe ins erted an advertisement in the "For Sal e" column of the Kenora Miner and News. We have received a checking copy. Thanks Mr. Kittle!

\section{The Golden Age of Mammals}

BY BRUCE A. McCORGUODALE IVuseum Assistant, Regrna.

CYPRESS HILLS REGION30 MILLION YEARS AGO

During the summer of 1950 the staff of the Provincial Museum, Regina, made two trips to the Cypress Hills region where they conducted extensive exploration andexca vations in the locality 12 miles northwest of Eastend, Sask., for the purpose of collecting fossil material of the Oligocene period - age, 30 million years.

The fossil bearing formation consists of a river delta deposit of sand, sandstone and conglomerate, which contains a great abundance of mammalian and reptillian remains, indicating that animal life of the Oligocene age was very prolific. In addition to the fact that the fossils were very abundant they were also in a remarkably excellent state of preservation and as a re sult of this the museum expeditions recovered several hundred well preserved specimens, many of which will prove of great importance in yielding information and promoting interest in the faunal life of Saskatchewan of the past.

Let us try to visualize in brief the general life forms and environmental conditions of the Saskatchewan, 30 million years ago as revealed by and in co-ordination with the specimens recovered from the Cypress Hills.

The dominant life form of the area was a large subaquatic mammal called a Titanothere. Ranging in bul $\mathrm{k}$ size up to that of a modern elephant, this great beast had blunt horns paired laterally on the forward extremity of its nose and in general body form resembled the present day Rhinoceras. Its food con sisted mostly of soft succul ent vegetation of marshy origin. This animal is rep re sented in the coll ection of fossils by several single and double lower mandibles, several horns, numerous individual teeth, a scapula, two femurs a radius and ulna, a pelvis and several ribs and verterbra The most important of these finds is a well preserved skull of an immature individual of a primitive smaller genera of the Titanothere group In addition two skull portions of Titanotheres of a more advanced genera were found.

of secondary importance but probably of greater abundance, compared to the Titanotheres, were a group of several species of Hyracodonts which were small hornless a nimals, terrestial and fleet of foot. These animals, which are early ancestors of the modern rhinoceras, are repre sented in the collection by a well preserved skull, several individual teeth, numerous lower mandibles and a few skeletal parts. In addition to these the true primitive rhinoceras, Caenopus, is represented by upper and lower mandibles.

Also in abundance during Oligocene times were several members of the deer group, represented by species of $\mathrm{Hy}$ pertragulus and Lep tomeryx which were small, swift and delicate animals no larger than the modern dog. Teeth of several species of this group were recovered from the depo sits by the Mus eum expeditions.

An extinct goup of animals, Entelodonts, related to the pig family and resembling them some what in habits and hody form, were also quite prolific in marshy area. This faunal type is represented in the discoveries by a relatively rare find, an incomplete skull and two other individual teeth.

Rodents, reptiles and small carnivores were numerous during Oligocene times as evidenced by the recovery of several small bones and teeth of these groups. 